\title{
A dimensão musical na minissérie $O$ brado retumbante: princípios e articulações ${ }^{1}$
}

\section{Irineu Guerrini Jr.}

Doutor em Ciências da Comunicação pela Universidade de São Paulo (USP). Professor da Faculdade Cásper Líbero. Já foi produtor, diretor e narrador da TV Cultura de São Paulo; diretor das emissoras Cultura AM e FM; produtor, diretor e apresentador da Seção Brasileira da BBC em Londres; avaliador e negociador da TV Cultura para programas produzidos por terceiros; e codiretor da TV Escola, do MEC.

E-mail: irineu.guerrini@gmail.com
${ }^{1}$ Versão revista e ampliada de trabalho apresentado ao GP - XVI Encontro dos Grupos de Pesquisa em Comunicação, evento componente do XXXIX Congresso Brasileiro de Ciências da Comunicação.
Resumo: Este trabalho procura analisar a trilha musical da minissérie $O$ brado retumbante (2012), produzida pela Rede Globo, e demonstrar a importância da criação musical para a construção de significados nesse gênero específico de ficção televisiva. Para tanto, primeiramente é fornecida uma noção do argumento da minissérie. Em seguida, logo após a enumeração de algumas publicações importantes que tratam de trilhas musicais, são apresentados alguns conceitos desenvolvidos em Unheard melodies: narrative film music (Claudia Gorbman, 1987), uma conhecida obra desse campo. Na sequência, é apresentada uma análise da trilha musical e parte do primeiro capítulo dessa minissérie. Em seguida, busca-se relacionar certas características da articulação audiovisual com os conceitos vistos anteriormente.

Palavras-chave: Televisão; Trilha musical; Fiç̧ão televisiva brasileira.

The musical dimension in the miniseries $O$ brado retumbante: principles and articulations

Abstract: The aim of this work is to analyze the soundtrack of the miniseries O brado retumbante (2012), produced by Rede Globo, and to demonstrate the importance of the musical creation for the construction of meanings in this specific genre of television fiction. Therefore, first is provided a notion of the miniserie's argument. Next, the enumeration of some important publications about musical score, some concepts developed on Unheard melodies: narrative film music (Claudia Gorbman, 1987), a known work of this field, are presented. Then, a musical score analysis and part of the first chapter of the miniseries are presented. Finally, some characteristics of audiovisual articulation and concepts already seen are connected.

Keywords: Television; Musical score; Brazilian TV fiction. 


\section{Introdução}

Em sua forma atual, a concepção e a produção de uma minissérie de televisão diferem muito das de uma telenovela: enquanto nesta a emissão é diária e exige muita rapidez em sua realização, e sua história pode ser alterada ou mesmo encurtada a qualquer momento, dependendo da reação do público; uma minissérie dispõe de mais tempo para ser pensada e produzida, sua realização pode ser mais elaborada e a história normalmente é fechada, isto é, não é modificada durante o decorrer da transmissão de seus episódios. Além disso, não conta com merchandising, tão comum nas novelas. Há também uma diferença importante na trilha musical: uma novela costuma ser uma vitrine para canções já existentes que são utilizadas com boa dose de arbitrariedade, pois o que interessa para a emissora é agrupá-las em CDs "nacionais" e "internacionais" e lançá-los no mercado. No caso da Rede Globo, essas compilações são comercializadas pela Som Livre, do mesmo grupo empresarial. Já numa minissérie, em geral não ocorre esse fenômeno, e sua trilha musical costuma ser mais elaborada e funcional, sem a arbitrariedade comumente encontrada nas trilhas das telenovelas, possibilitando, assim, um trabalho mais autoral. Além disso, a pesquisa no campo das trilhas musicais de minisséries brasileiras é quase inexistente.

Neste trabalho, procurou-se primeiramente fornecer uma noção do argumento de $O$ brado retumbante; em seguida, logo após a enumeração de algumas publicações importantes que tratam de trilhas musicais, trabalhou-se com alguns conceitos desenvolvidos em uma conhecida obra específica desse campo, citada mais adiante. A análise da trilha musical dos primeiros dezessete minutos e meio do primeiro capítulo dessa minissérie possibilita a comprovação do grau de elaboração da trilha, e, em algumas passagens de maior interesse, a utilização de obras musicais já existentes demonstra uma funcionalidade que frequentemente é perdida nas telenovelas. Em seguida, tentou-se relacionar certas características da articulação audiovisual com os conceitos vistos anteriormente.

\section{O brado retumbante}

O brado retumbante foi ao ar em 2012 pela Rede Globo, e já seu título possui uma referência musical, pois, como se sabe, é uma expressão que consta da letra do Hino Nacional brasileiro. A história gira em torno de um deputado federal que, por uma série de contingências, é eleito para a presidência da Câmara dos Deputados. A morte do presidente da República e de seu vice num acidente faz que ele acabe ascendendo ao cargo máximo do Poder Executivo. Políticos corruptos, relações problemáticas com os países vizinhos, casos passionais interferindo na vida pública do protagonista, um presidente que anda de moto pelas avenidas de Brasília: há um componente fortemente jornalístico em seu enredo, que se passa na atualidade brasileira. Realidade e ficção se confundem.

Vale observar que não é a primeira vez que se pensou nesse título para uma obra audiovisual, dando-Ihe um sentido irônico. Numa entrevista para o autor deste trabalho, realizada em 9 de janeiro de 2001, Carlos Diegues (apud GUERRINI JÚNIOR, 2009: 172), falando de seu filme Os herdeiros, conta:

O filme chamava-se originalmente $O$ brado retumbante. Eu filmei até o final com esse título. Quando o filme foi para a censura, uma das implicâncias da censura foi exatamente com o título, porque o "brado retumbante" era do hino nacional. O título Os herdeiros só veio depois que o filme ficou pronto.

\section{Fundamentação teórica: apanhado bibliográfico, conceitos e categorias}

Hoje em dia, já é grande o número de livros, teses, artigos e outros trabalhos acadêmicos e não acadêmicos que exploram diferentes aspectos do uso da música combinada com a dramaturgia no cinema. Do pioneiro Music for the 
films, de Leonid Sabaneyev, publicado pela primeira vez em 1935, a Comporre per il cinema: teoria e prassi della musica nel film, do conhecido compositor Enio Morricone e de Sergio Miceli (2001), passando pelo clássico Composing for the films, de Hans Eisler e Teodor Adorno (1945); The technique of film music, de Roger Manvell e John Huntley (1975); La musique au cinéma, de Michel Chion (1995); o pioneiro Sygchronos, do brasileiro Ney Carrasco (2003), e muitos outros, o pesquisador já dispõe de valiosas ferramentas para estudar a articulação da música com imagens e outros sons com uma fundamentação teórica satisfatória. A grande maioria desses trabalhos, como comprovam os títulos anteriores, referese à música composta para filmes, não para trabalhos televisivos.

Uma obra já clássica, bastante citada em trabalhos acadêmicos, e que será tomada como base para a fundamentação teórica deste pequeno trabalho é Unheard melodies: narrative film music, da professora e pesquisadora americana Claudia Gorbman, que teve sua primeira edição lançada em 1987 pela Universidade de Indiana. Mesmo considerando-se que a autora se refere a obras cinematográficas, os conceitos e categorias expostos em seu livro e em outras obras podem ser, em boa medida, e principalmente aqueles mais genéricos, aplicados também à dramaturgia para televisão, especialmente quando uma trilha musical produzida para uma minissérie se aproxima do grau de complexidade de trabalhos para o cinema.

Em seu livro, Gorbman, mesmo admitindo que a fronteira entre essas duas categorias pode não ser muito nítida, estabelece uma distinção básica entre "música diegética" e "música não diegética". Esses termos vêm do grego diegesis = narrativa. Música diegética é a "música que (aparentemente) vem de uma fonte dentro da narrativa" (GORBMAN, 1987: 22). Isto é, está dentro da cena, mesmo que não vejamos sua fonte. Um personagem tocando um instrumento, a música que vem do rádio de um carro, uma pessoa que passa assobiando na calçada (mesmo que não a vejamos), produzem "música diegética". "Música não diegética" (Gorbman, 1987: 14) também conhecida como "música de fundo" é música que está fora da cena, música para acompanhar um segmento de filme.

Em seu livro, Gorbman estabelece os princípios de composição, mixagem e edição de uma trilha musical, que são:

${ }^{2}$ Ao menos pelo espectador comum.

I. Invisibilidade: o aparato técnico da música não diegética não deve ser visível. II. "Inaudibilidade": a música não foi feita para ser ouvida conscientemente². III. Significadora de emoção: a música pode estabelecer climas específicos e enfatizar emoções particulares [...] mas é significadora de emoção em si mesma. IV. Pontuação narrativa: - referencial/narrativa [...] ex., indicando pontos de vista, fornecendo demarcações formais [...] - música conotativa: a música "interpreta" e "ilustra" eventos narrativos. V. Continuidade: a música proporciona continuidade formal e rítmica [...] VI. Unidade: [...] A música auxilia na construção da unidade formal e narrativa. VII. Uma dada trilha musical pode violar qualquer dos princípios acima, contanto que a violação esteja a serviço dos outros princípios. (Ibid.: 73, tradução nossa).

Em outra passagem da mesma obra, a autora contrasta o particular, o prosaico, o presente e o literal (sequências sem música) com o universal, o poético, o mítico e o simbólico (sequências com música) (Ibid.: 82).

Dos poucos trabalhos existentes que se debruçam especificamente sobre a música da dramaturgia na televisão no Brasil, este autor conhece: A trilha sonora na telenovela brasileira, de Rafael Roso Righini; Som Livre e trilhas sonoras das telenovelas: pressupostos sobre o processo de difusão da música, de Heloísa Maria dos Santos Toledo; e Rede Globo e indústria fonográfica: um negócio de sucesso, de Márcia Tosta Dias. Há também uma dissertação de mestrado para a Unicamp, de autoria de André C. Antonietti (2012), que trata da música da minissérie Anos rebeldes. 
${ }^{3}$ Quando se trata de qualquer gênero cantado, sua letra obviamente tem um significado "literário".
Uma questão importante que deve ser mencionada é a do significado musical. Entramos em terreno escorregadio quando desejamos atribuir significados extramusicais a determinada música, especialmente música instrumental, sem palavras ${ }^{3}$. Seria inviável num trabalho desta dimensão determo-nos de maneira mais aprofundada nessa questão, citando exemplos ou autores. Contudo, é certo que a posição mais aceita, atualmente (mas longe de ser uma unanimidade entre os estudiosos) é a de que os significados objetivamente verificáveis de uma composição musical são sintáticos, isto é, referem-se às relações entre os próprios componentes puramente musicais, e não semânticos, ou seja, referentes a valores extramusicais. Costuma-se dizer que a música é a mais autorreferente das artes, e que as emoções que ela pode transmitir não podem ser traduzidas em palavras.

Por outro lado, quando uma composição musical está associada a imagens, falas e ruídos, como em filmes, novelas ou minisséries, a situação é outra: ela pode se articular com esses outros elementos de uma obra audiovisual e ser parte importante de significados extramusicais.

\section{A trilha musical em $O$ brado retumbante}

Uma audição atenta à trilha musical da minissérie, de autoria de Eduardo Queiroz, revela - o que depois foi confirmado por seu autor - que foram utilizados os seguintes instrumentos: orquestra de cordas, piano, vibrafone, trompete, baixo acústico, bateria e sintetizadores. No quarto capítulo ouve-se também um conjunto regional, formado por clarinete, bandolim, violão e pandeiro.

Frequentemente são motivos musicais curtos, formados por poucas notas e executados por poucos instrumentos, que lembram o estilo contido de trilhas musicais de alguns filmes norte-americanos contemporâneos - não os blockbusters juvenis, mas os indies (produções independentes), especialmente os dramas, que costumam trabalhar com orçamentos mais modestos (para os padrões de Hollywood) e não contam com a participação de orquestras sinfônicas (como muitas vezes notamos nos blockbusters, que repetem um estilo iniciado nos anos 1930, de caráter exuberante e com origens no romantismo musical).

Como já foi dito, a dimensão musical da minissérie começa já com seu título, retirado do Hino Nacional. E contrastando ironicamente com a falta de escrúpulos na política, o patriotismo lembrado pela expressão retirada do hino brasileiro junta-se a duas outras composições também muito emblemáticas da "pátria": os primeiros compassos da protofonia de I/ Guarany, de Carlos Gomes - há dezenas de anos música de abertura de $A$ voz do Brasil -, num arranjo especial para a minissérie, e o início do samba-exaltação "Aquarela do Brasil", de Ary Barroso, tocado solitária e melancolicamente no clarinete pelo protagonista, em seu quarto, que constitui a cena final do primeiro capítulo. Em outra passagem, o presidente assiste a uma ópera no Teatro Municipal do Rio de Janeiro - vemos e ouvimos um de seus trechos, como será comentado adiante.

Constata-se, também, haver muita música não diegética em todos os episódios, composta especialmente para a minissérie, que pode comentar, enfatizar, antecipar, recapitular ou contrastar ironicamente com as imagens.

\section{A música no primeiro capítulo da minissérie: uma amostra}

Uma primeira constatação é a de que em todo o primeiro capítulo, com exceção da cena final, do solo de clarinete pelo protagonista, ouve-se música não diegética, isto é, que não faz parte da cena, mas que a acompanha e com ela se articula.

Em seguida, uma análise da trilha musical dos primeiros dezessete minutos e meio desse episódio. Foram usados alguns termos musicais. Contudo, mesmo 
quem não está familiarizado com esses termos poderá constatar, com as indicações fornecidas por este trabalho, o quão elaborada é a trilha musical para um trecho equivalente a menos da metade de um único capítulo. Assim, procurou-se dar uma ideia, ainda que incompleta, da complexidade que pode atingir uma trilha musical de uma minissérie.

\section{O brado retumbante - 10 episódio}

Primeiros 17min30seg.

\begin{tabular}{|c|c|}
\hline $\begin{array}{l}\text { 1. Externa, dia - Plano geral dos prédios } \\
\text { do Congresso Nacional. Letreiro de } \\
\text { localização. }\end{array}$ & $\begin{array}{l}\text { Motivo curto no xilofone, formado por três notas: } \\
\text { mi, mi, fá. Percussão. }\end{array}$ \\
\hline $\begin{array}{l}\text { 2. Interna, dia - Corredor dos gabinetes } \\
\text { dos deputados. }\end{array}$ & \multirow{4}{*}{$\begin{array}{c}\text { Cordas em pizzicato apresentam outros motivos } \\
\text { curtos, sempre formados por três notas: } \\
\text { ré, fá, lá; } \\
\text { ré, fá, si; } \\
\text { sol sustenido, lá, si; } \\
\text { si, lá, sol sustenido (inversão do penúltimo). } \\
\text { Estes motivos aparecem em diferentes } \\
\text { configurações, até a cena } 5 .\end{array}$} \\
\hline $\begin{array}{l}\text { 3. Interna, dia - Reunião de deputados } \\
\text { corruptos para definir o presidente da } \\
\text { Câmara, que deverá apenas completar um } \\
\text { mandato. }\end{array}$ & \\
\hline $\begin{array}{l}\text { 4. Interna, dia - Paulo Ventura, } \\
\text { discursando na Câmara dos Deputados, } \\
\text { acusa de corrupção o ministro da Educação } \\
\text { Florando Pedreira e o presidente Monte } \\
\text { Santo. }\end{array}$ & \\
\hline $\begin{array}{l}\text { 5. Interna, dia - De novo, a reunião para } \\
\text { escolher o presidente interino da Câmara. } \\
\text { Paulo Ventura acaba sendo escolhido, por } \\
\text { ser considerado inócuo para os interesses } \\
\text { daqueles deputados. }\end{array}$ & \\
\hline 6. Imagem de abertura. & $\begin{array}{l}\text { Tema marcial, épico, com destaque logo no } \\
\text { início para o prato e a caixa da bateria, Melodia } \\
\text { solada por trombone e depois trompas tocando } \\
\text { em quartas (na verdade, simulações desses } \\
\text { instrumentos produzidos por sintetizador) e baixo } \\
\text { com pulsação marcante. }\end{array}$ \\
\hline $\begin{array}{l}\text { 7. Externa, noite - Prédio de apartamentos } \\
\text { no Rio de Janeiro. }\end{array}$ & \multirow[b]{2}{*}{$\begin{array}{l}\text { Sem música (A ausência de música também faz } \\
\text { parte do planejamento da trilha, pois estabelece } \\
\text { um contraste muito forte com as cenas com música. } \\
\text { Quando a música retorna, cresce em importância). }\end{array}$} \\
\hline $\begin{array}{c}\text { 8. Interna, noite - Diálogo entre Paulo } \\
\text { Ventura e sua esposa Antônia, professora } \\
\text { universitária. Vivem separados. Ele conta } \\
\text { a novidade a ela, e insiste que saiam e } \\
\text { jantem fora. Ela recusa, dizendo que tem } \\
\text { que preparar uma aula. "Chama uma das } \\
\text { suas correligionárias; certamente deve ter } \\
\text { alguma com fome", são suas palavras, que } \\
\text { encerram a cena. }\end{array}$ & \\
\hline 9. Externa, noite - Avenida de Brasília. & $\begin{array}{l}\text { Sem música. Mas nos segundos finais, já } \\
\text { ocorre um fade-in da música que } \\
\text { aparece na cena seguinte. }\end{array}$ \\
\hline $\begin{array}{l}\text { 10. Externa, noite - Paulo com esposa do } \\
\text { senador no carro dela. Ela está dirigindo. }\end{array}$ & $\begin{array}{l}\text { Voz entoa notas sem letra acompanhada de guitarra } \\
\text { e piano, em estilo que lembra gêneros americanos. }\end{array}$ \\
\hline $\begin{array}{l}\text { 11. Externa, noite - Os dois testemunham } \\
\text { um acidente: um carro bate numa moto. } \\
O \text { condutor da moto é atirado no chão. }\end{array}$ & $\begin{array}{l}\text { Forte percussão. Baixo. Depois, vibrafone fazendo } \\
\text { um solo baseado nas notas dó, dó, mi bemol, dó, fá. }\end{array}$ \\
\hline $\begin{array}{l}\text { 12. Externa, noite - Chega a polícia. } \\
\text { Os policiais sugerem um suborno. Paulo } \\
\text { recusa. }\end{array}$ & $\begin{array}{l}\text { Sem música, estabelecendo novo contraste. } \\
\text { Ouvem-se apenas sirene e voz que supostamente } \\
\text { sai do rádio do carro dos policiais }{ }^{4} \text {. }\end{array}$ \\
\hline
\end{tabular}

${ }^{4}$ Este é um bom exemplo de som diegético: embora não vejamos sua fonte, faz parte da cena. recusa. 


\begin{tabular}{|c|c|}
\hline $\begin{array}{l}\text { 13. Externa, noite - Paulo com esposa do } \\
\text { senador do carro. Despedem-se. }\end{array}$ & $\begin{array}{c}\text { Sem música, no início. Depois, tema com quatro } \\
\text { notas: mi, mi, mi, dó com terças abaixo, tocadas em } \\
\text { oitavas diferentes pelas cordas em pizzicato. }\end{array}$ \\
\hline 14. Interna, noite - Paulo testemunhando. & $\begin{array}{l}\text { Música anterior invade os primeiros segundos } \\
\text { dessa cena. Depois, solo de flauta, com motivos em } \\
\text { três notas. }\end{array}$ \\
\hline $\begin{array}{l}\text { 15. Interna, noite - Paulo com seu } \\
\text { colaborador Saldanha. }\end{array}$ & $\begin{array}{c}\text { Música anterior continua nessa cena, mas depois } \\
\text { vai desaparecendo. }\end{array}$ \\
\hline $\begin{array}{l}\text { 16. Externa, noite - Helicóptero sobre o } \\
\text { mar. Transporta o presidente Monte Santo } \\
\text { e seu vice. Relâmpagos. }\end{array}$ & $\begin{array}{l}\text { Motivos de três notas (mais uma vez) tocados no } \\
\text { piano. Acordes pontuais produzidos pelas cordas. } \\
\text { Flauta também tocando motivos de três notas. }\end{array}$ \\
\hline $\begin{array}{l}\text { 17. Interna, noite - Quarto de Paulo, que } \\
\text { está alcoolizado. }\end{array}$ & Música da cena anterior continua nesta. \\
\hline 18. Externa, noite - Helicóptero. & Música continua. \\
\hline $\begin{array}{l}\text { 19. Interna, noite - Quarto de Paulo. Seu } \\
\text { amigo Saldanha finalmente consegue } \\
\text { entrar e conta que o presidente e o vice } \\
\text { morreram em acidente com o helicóptero. } \\
\text { Paulo custa a acreditar e Saldanha diz para } \\
\text { ele ligar a TV. }\end{array}$ & Sem música. \\
\hline $\begin{array}{l}\text { 20. Tela de TV - No telejornal, } \\
\text { apresentadora dá a notícia: o helicóptero } \\
\text { explodiu, matando o presidente e o vice. }\end{array}$ & $\begin{array}{l}\text { Pequenos motivos no piano tendo como } \\
\text { fundo acordes longos, executados por vários } \\
\text { instrumentos. }\end{array}$ \\
\hline $\begin{array}{l}\text { 21. Interna, noite - Quarto de Paulo. } \\
\text { Saldanha diz: "Você é o novo presidente } \\
\text { da República, Paulo". }\end{array}$ & Música continua. \\
\hline $\begin{array}{c}\text { 20. Interna, noite - Apartamento de } \\
\text { Antônia. Paulo chega, implora para que } \\
\text { ela volte para ele e diz para ela ligar a } \\
\text { televisão. }\end{array}$ & Música continua. \\
\hline $\begin{array}{l}\text { 21. Tela de TV - No telejornal, } \\
\text { apresentadora diz que Paulo Ventura, } \\
\text { como presidente da Câmara, deve assumir } \\
\text { a presidência. }\end{array}$ & Sem música. \\
\hline $\begin{array}{l}\text { 22. Interna, dia - Mãe de Paulo liga } \\
\text { querendo saber o que é essa história de } \\
\text { ele virar presidente. }\end{array}$ & Sem música. \\
\hline $\begin{array}{l}\text { 23. Tela de TV - Apresentadora completa a } \\
\text { informação. }\end{array}$ & Sem música. \\
\hline $\begin{array}{l}\text { 24. Interna, noite - Apartamento de } \\
\text { Antônia. Paulo diz para sua esposa ficar } \\
\text { com ele, pelo menos pelo próximos } \\
\text { dezoito meses. Ela aceita, com algumas } \\
\text { condições. }\end{array}$ & $\begin{array}{l}\text { Sem música, até Paulo dizer "Não me deixe sozinho } \\
\text { agora", quando entra tema de quatro notas - ré, } \\
\text { sol ré, mi, em tonalidade menor, primeiro feito pelo } \\
\text { piano, depois pela orquestra de cordas. }\end{array}$ \\
\hline
\end{tabular}

\section{Algumas passagens de maior interesse musical}

\section{Capítulo 1}

Como já foi assinalado, no final desse capítulo, Paulo Ventura, que é clarinetista amador, sola, em seu quarto, um trecho de "Aquarela do Brasil", samba-exaltação por excelência, um dos melhores representantes de um gênero que floresceu principalmente durante o Estado Novo, e que canta as belezas da pátria. Embora o que se ouve seja uma versão instrumental, solada no clarinete, esse significado extramusical vem à tona, pois se trata de música amplamente conhecida, mesmo na atualidade. E como também já foi lembrado, há uma forte intenção irônica, ou seja, de estabelecer um contraste entre essa música que prega o amor à pátria e a realidade política abjeta. 
${ }^{5}$ A versão atualmente usada pelo programa A voz do Brasil é a de um arranjo pop, com o uso de guitarra elétrica.

\section{Capítulo 2}

Logo no início desse capítulo, um narrador off faz uma rápida biografia de Paulo Ventura. Em background (BG), o que ouvimos é uma versão dos primeiros compassos da protofonia da ópera // Guarany originalmente para orquestra sinfônica, mas aqui solada num dos registros de um sintetizador. $O$ fato de ser utilizada como abertura para o programa $A$ voz do Brasil há dezenas de anos deve ter contribuído para que adquirisse um sentido fortemente "patriótico" também. Logo depois, ainda com o BG sob a voz do narrador, esse mesmo tema e algumas pequenas variações são acompanhados por uma percussão que lembra certos ritmos afro-brasileiros, como os do grupo Olodum ${ }^{5}$. Alta cultura e cultura popular fundem-se, o que remete à Tropicália.

\section{Capítulo 3}

O presidente Paulo Ventura veio prestigiar a abertura da temporada lírica do Theatro Municipal do Rio de Janeiro. Está sendo apresentada a ópera Roméo et Juliette, de Gounod, e ouvem-se seus compassos finais, com o casal de personagens em cena. O presidente está no camarote. Na saída do teatro, numa sequência de produção muito elaborada, o presidente e seu principal agente de segurança são atingidos por tiros de revólver. Imediatamente são levados às pressas para um hospital, e acompanhando essas imagens da corrida dos carros presidenciais e depois no hospital, ouvimos sons graves na forma de uma pulsação rápida e regular, que enfatizam o suspense e o sentido de urgência dessas cenas.

\section{Capítulo 4}

Numa festa de recepção no palácio presidencial, a música é feita por um conjunto regional. Embora, na narrativa trate-se de música diegética - os músicos estão efetivamente em cena-na verdade o que ouvimos é um playback. Esse recurso técnico é identificável pela qualidade sonora muito "limpa", de gravação feita em estúdio de áudio e não em meio a todos os convidados para a festa, mas, acima de tudo, porque os instrumentos que aparecem em cena não são exatamente o que ouvimos, como a presença de um banjo em cena (e não no áudio) e a ausência de um clarinete, que na verdade sola a melodia de um dos maiores clássicos da música popular brasileira: "Carinhoso", de Pixinguinha e João de Barro. Paulo Ventura, dançando com sua mulher, chega a cantarolar um trecho de sua letra: "Bate feliz quando te vê/ E os meus olhos ficam sorrindo/ E pelas ruas vão te seguindo/ Mas, mesmo assim, foges de mim". Pouco depois, é o próprio presidente que sola um trecho de "Feito de oração", de Noel Rosa e Vadico, em seu clarinete. Chega seu corrupto e bajulador tio Bejo e comenta, mostrando sua ignorância musical: "Nosso Glenn Miller" - o conhecido bandleader tocava trombone, não clarinete! Ainda na festa, mais adiante, pode-se ouvir "Atraente", de Chiquinha Gonzaga, também tocada por um clarinete, em termos dramatúrgicos diegético, mas que na verdade não está na cena, mas no playback.

\section{Capítulo 5}

Paulo Ventura tem um filho que rejeita, por ser homossexual. Já na infância do menino, conflitos com o pai são permanentes. Ele acaba fugindo de casa e em Paris, passa por uma operação que completa sua transexualidade. Agora ele (ela) se chama Julie. Numa ocasião, de volta ao Brasil, ela sofre uma brutal agressão física, e tem que ser hospitalizada. Ao mesmo tempo, um dos principais inimigos políticos de Paulo Ventura explora o fato de o presidente tentar esconder sua filha, chamando-o de homofóbico na Câmara dos Deputados e perguntando se ele não escondia outros fatos.

Ventura resolve enfrentar a opinião pública e vai à televisão pedir perdão à filha, Suas palavras: "Estou aqui para pedir desculpas públicas a minha filha Julie e a todos que já sofreram com essa dor. E esperar que eles possam viver num 
mundo mais pacífico e acolhedor, onde realmente nada do que é humano nos seja estranho". Mas Julie, já recuperada, volta aos Estados Unidos, onde morava.

A última cena do capítulo, já com os créditos finais, mostra Julie no interior do avião e depois a aeronave decolando. Nessa sequência, mais música já existente e não diegética: o samba "Juízo final", de Nelson Cavaquinho, cantado por seu compositor. Sua letra vai bem ao encontro das palavras do presidente: "O sol há de brilhar mais uma vez/ A luz há de chagar aos corações/ Do mal será queimada a semente/ O amor será eterno novamente/ É o Juízo Final, a história do bem e do mal/ Quero ter olhos para ver a maldade desaparecer".

Vale observar que essa mesma composição de Nelson Cavaquinho seria usada, em 2016, numa novela da Rede Globo: A regra do jogo - nesse caso com maior destaque, pois está na abertura de todos os capítulos, numa interpretação de Alcione.

\section{Capítulo 8}

A cena final deste capítulo - e da minissérie - se passa num cenário de debate, pela TV, para a eleição presidencial. Os debatedores são os candidatos Paulo Ventura e Floriano Pedreira. Ventura é quem inicia o debate, anunciando que, ao contrário do que tinha afirmado quando assumira o cargo presidencial por acidente, vai concorrer à eleição. Quando ele começa a falar, e até o final, ouve-se um solo de trompete desacompanhado, que insiste num motivo curto, acentuando, de maneira muito expressiva, as falas do herói solitário. $\mathrm{O}$ motivo é repetido até as últimas palavras do candidato: "Eu conto com o seu voto", fechando a minissérie.

\section{Os princípios de Gorbman presentes na minissérie}

Nos princípios, já citados, estabelecidos por Claudia Gorbman, o primeiro obviamente está presente: a invisibilidade do aparato técnico para a música não diegética. A minissérie, contudo, vai um pouco adiante, pois chega a utilizar playbacks (ou seja, uma fonte invisível) para simular uma música na verdade diegética, ou seja, uma fonte visível. E ainda com a troca de alguns instrumentos - é o caso da cena da recepção no palácio presidencial.

O segundo princípio, da "inaudibilidade", tem caráter geral, isto é, vale para toda e qualquer obra audiovisual de ficção. Ou seja, especialmente nas sequências com música não diegética, o espectador comum, via de regra, não costuma ter consciência da música utilizada, embora seja por ela influenciado.

Quanto aos princípios da música como "significadora da emoção", e como "pontuação narrativa", fica evidente, pelos exemplos dados, que ela cumpre esses papéis.

Entretanto, tais significados extramusicais têm de ser sempre considerados do ponto de vista da articulação da música com as imagens, falas e outros sons.

O papel da música ao auxiliar a "continuidade" e a "unidade" da obra são facilmente detectáveis em algumas cenas: pode-se notar, nas sequências com música não diegética analisadas anteriormente que, em algumas passagens, o mesmo motivo musical é utilizado numa sucessão de cenas, contribuindo para a continuidade de toda a minissérie. Em outras passagens, essa utilização estendida do mesmo motivo musical se dá até em situações dramáticas muito diferentes entre si: é muito intenso, nesses casos, o papel da música na construção da unidade de uma obra audiovisual. Simultaneamente, essa utilização dos mesmos motivos em cenas muito diferentes entre si, embora funcionando muito bem na articulação audiovisual, reforça a ideia de que uma mesma sequência musical, com seu inerente significado sintático e autorreferente, pode adquirir significados extramusicais diferentes - portanto, semânticos, quando associada a diferentes imagens, falas e ruídos. Como o próprio compositor afirmou: 
Queria fazer uma trilha que tivesse um tema que fosse usado em toda a trilha. Você pode ouvir este tema em quase todas as músicas, bem como a orquestração, que faz parte do conceito sonoro da trilha, usando pizzicatos, piano e vibrafone. (Eduardo Queiroz, depoimento via e-mail ao autor desta pesquisa).

O último princípio estabelecido por Gorbman (1987: 73) afirma que "uma dada trilha musical pode violar qualquer dos princípios anteriores, contanto que a violação esteja a serviço dos outros princípios". Cremos que não se aplica nesta minissérie.

Em outra passagem, como já foi afirmado, a autora contrasta sequências sem música com sequências com música (Ibid.: 82). Também aqui podemos detectar esse contraste em algumas cenas apresentadas. Tomem-se, como exemplos, as cenas de 1 (prédios do Congresso Nacional) e 6 (abertura), que contêm música, e as cenas 12 (com os policiais) e 22 (a mãe do presidente falando no orelhão), que não contêm música. Nesses exemplos, fica clara a distinção mencionada.

\section{Considerações finais}

Em primeiro lugar, deve-se insistir na importância da trilha musical como parte da articulação dramática dessa minissérie. Cremos que qualquer espectador, ao assistir essa obra da ficção para a televisão e tendo ajuda de um trabalho como este, pode perceber o quanto faria falta a trilha musical se retirada. É oportuno lembrar que essa importância da música articulada com uma ação dramática é bem antiga: mesmo se nos restringirmos à cultura do mundo ocidental, ela remonta ao teatro grego, com seu coro e sua "orquestra" - palavra que originalmente designava o local onde os músicos ficavam numa representação teatral.

Em segundo lugar, cremos que a análise desenvolvida foi suficiente para demonstrar quão elaborada pode ser uma trilha musical para uma minissérie, o que a aproxima de muitas trilhas desenvolvidas para filmes de longa-metragem.

Em terceiro lugar, deve-se ressaltar que o trabalho de um compositor de trilhas é muito diferente daquele de quem compõe uma obra para ser apresentada autonomamente. Aqui também vale reproduzir uma observação de Eduardo Queiroz:

Busco sempre manter uma boa relação com os diretores e produtores. Gosto de fazer trilhas e, portanto, gosto do trabalho criativo em equipe. Este trabalho provoca, instiga e leva a resultados inesperados. Acho que este é meu método: trabalho de equipe. No caso específico do Brado, a minha relação com o diretor foi sempre excelente e muito aberta a ideias. Foi meu primeiro trabalho com o roteirista, e durante a produção também pudemos desenvolver uma relação de confiança criativa. O tema de abertura foi feito a partir de uma sugestão dele. (Depoimento via e-mail ao autor desta pesquisa).

Em quarto e último lugar, este pesquisador espera que um trabalho como este contribua, mesmo que modestamente, para estimular o estudo da música combinada com a ficção televisiva, especialmente nas minisséries - algo ainda incipiente em nosso país.

\section{Referências}

ANTONIETTI, A. C. A música da minissérie brasileira no exemplo de Anos Rebeldes. Campinas: Unicamp, 2012. Mimeografado.

CARRASCO, N. Sygkhronos: a formação da poética musical no cinema. São Paulo: Via Lettera; Fapesp, 2003.

CHION, M. La musique au cinéma. Paris: Fayard, 1995. 
DIAS, M. T. Rede Globo e indústria fonográfica: um negócio de sucesso. In: BRITTO, V.; BOLAÑO, C. R. S. Rede Globo: 40 anos de poder e hegemonia. São Paulo: Paulus, 2005. p. 214-226.

EISLER, H.; ADORNO, T. Composing for the films. London: Atlantic Highlands; New Jersey: Athlone, 1994.

GORBMAN, C. Unheard melodies: narrative film music. Bloomington: Indiana University, 1987.

GUERRINI JÚNIOR, I. A música no cinema brasileiro: os inovadores anos sessenta. São Paulo: Terceira Margem, 2009.

MANVELL, R.; HUNTLEY, J. The technique of film music. London; New York: Focal, 1975.

MORRICONE, E.; MICELI, S. Comporre per il cinema: teoria e prassi dela musica nel film. Venezia: Marsilio, 2001.

O BRADO retumbante. Direção: Gustavo Fernandez e André Felipe Binder. Intérpretes: Domingos Montagner, Maria Fernanda Cândido, Otávio Augusto e Leopoldo Pacheco. Autoria: Euclydes Marinho. Rio de Janeiro: Som Livre, 2012. 2 DVD (343 min), son., color., digital. Minissérie de televisão em oito capítulos.

RIGHINI, R. R. A trilha sonora da telenovela brasileira: criação à finalização. São Paulo: Paulinas, 2004.

SABANEYEV, L. Music for the films. London: Sir Isaac Pitman \& Sons, 1978.

TOLEDO, H. M. S. Som Livre e trilhas sonoras das telenovelas: pressupostos sobre processo de difusão da música. In: GUERRINI JÚNIOR, I.; VICENTE, E. (Org.). Na trilha do disco: relatos sobre a indústria fonográfica no Brasil. Rio de Janeiro: E-papers, 2010. p. 23-40. 